\title{
Examining the Relationship of Self-Knowledge with Quality of Work Life and Mental Health of High School Managers in Nimrouz
}

\author{
Hossein Jenaabadi \\ MA Student of General Psychology, Department of Psychology, Zahedan Branch, Islamic Azad University, \\ Zahedan, Iran \\ Email: hjenaabadi@gmail.com
}

Received 5 March 2015; accepted 26 April 2015; published 19 August 2015

Copyright (C) 2015 by author and Scientific Research Publishing Inc.

This work is licensed under the Creative Commons Attribution International License (CC BY).

http://creativecommons.org/licenses/by/4.0/

(c) (i) Open Access

\section{Abstract}

The present study aimed to examine the relationship of self-knowledge with quality of work life and mental health of high school managers in Nimrouz. This was a descriptive-correlational study, the statistical population of which consisted of all high school managers in Nimrouz in the 2014-15 academic year ( $\mathrm{N}=90)$. In this study, Rastogi's Self-Concept Scale including 51 items, Mental Health Questionnaire containing 28 items, and Quality of Work Life Survey with 24 items were used. To determine the validity of these three questionnaires, content validity was applied. Moreover, using Cronbach's alpha coefficient, their reliability was examined, for which the alpha coefficients were $0.89,0.92$, and 0.81 , respectively. To analyze the obtained data, the Pearson correlation coefficient, regression analysis, independent t-test, and one-way analysis of variance were applied. Results indicated that self-knowledge was directly and significantly correlated with dimensions of quality of work life and mental health of managers. Additionally, there was a significant relationship between managers' quality of work life and mental health. Findings demonstrated that selfconfidence, sociability, and health and sex appropriateness were the best predicators of quality of work life and feeling of shame and guilt, abilities, and present, past, and future were the best predicators of mental health. Moreover, the level of self-knowledge, quality of work life, and mental health of male and female managers were alike. Considering managers' level of education, a significant difference was found considering managers' self-knowledge; however, no significant difference was found between quality of work life and mental health of managers. Given managers' 
years of experience, a significant difference was observed with regard to managers' self-knowledge and mental health.

\title{
Keywords
}

\author{
Self-Knowledge, Quality of Work Life, Mental Health, Managers
}

\section{Introduction}

Nowadays, improving the quality of work life is one of the most important objectives of various organizations and those who work for these organizations. When an individual's quality of work life improves, he/she becomes eager to work harder. This results in creating a creative and lively environment within a group or an organization which, given technological and equipment standards, increases the level of productivity beyond the expected results (Khadivi \& Alei, 2007).

The results of Keramati \& Roshan's (2005) study, entitled “The Relationship between School Managers' Self-Knowledge and Their Tricks to Manage Conflicts”, indicated that managers' self-knowledge was significantly correlated with solution-oriented tricks; however, it was not significantly related to non-interference trick and control trick.

Neyestani \& Monfarediraz (2009), in a study investigating the relationship between managers' self-knowledge and their tricks to manage conflicts in Bojnurd high schools, concluded that there was a significant relationship between managers' self-knowledge and their application of various conflict management styles. Moreover, managers' self-knowledge was significantly correlated with each style (i.e. competitive, cooperation, compromise, reconciliation, and avoidance).

Hosseini Frajam (2004), in a study entitled "Examining and Comparing Quality of Work Life of Teachers in Hamedan", found that teachers were to some extent satisfied with their quality of work life. Among the six components mentioned in this study, partnership had the best status.

Kheirandish (2004), in a study entitled "Quality of Work Life and Performance of Staff Working at Iran Khodro Diesel Company”, asserted that there was a significantly positive correlation between staff's quality of work life and performance.

Nazem (2006), examining the perception of quality of work life and its components in different regions of Islamic Azad University, indicated that there were significant differences in employees' mean scores on the components of work schedule, physical aspects of the job, observing justice in payments, authorities, employees' involvement, and the overall perception of quality of work life in various regions of Islamic Azad University.

In another study, Khadivi \& Alei (2007) studied the status of quality of work life of employees working at Islamic Azad University of Tabriz and concluded that quality of work life of employees was significantly related to their age, years of experience and gender.

Yavari, Amirtash, \& Tondnevsi (2009) compared quality of work life and its subscales among members of physical education faculties and departments in public universities and demonstrated that faculty members' age and years of experience were significantly related to their quality of work life. However, there was a significant difference between male and female subjects considering the dimension of social dependence of work life.

Pardakhtchi, Ahmadi, \& Arezoumand (2009) examined the relationship between quality of work life and job burnout of managers and teachers in Takestan and argued that there was a significant relationship between quality of work life and job burnout of teachers and managers. Among the components of the quality of work life, fair payment, social appropriateness and the general climate of working life respectively had the greatest impact on job burnout.

Gillian \& Callus (2003) conducted a study to develop indicators of quality of work life aiming at defining decent work in developed economies in Australia. The results showed that in general, more than 70 percent of employees had a positive attitude toward five indicators of occupational health, i.e. safety standards, behavior management, methods of teamwork, occupational safety, and lack of sexual harassment.

Krueger et al. (2002) concluded that the quality of work life was one of the presuppositions for inciting people and stated that there was a relationship between quality of work life and job satisfaction and its dimensions. Moreover, the findings demonstrated that quality of work life increased job satisfaction. 
Riley (2000) carried out a study to examine quality of work life, self-assessment, and life satisfaction among African-Americans and concluded that there was a reciprocal correlation between job satisfaction and quality of work life and that life satisfaction in general increased quality of life.

Pruijt (2000) in a study argued that there was a correlation between quality of work life and some indicators including absence, job satisfaction, personnel mobility, turnover, and belonging.

Accordingly, it is expected that managers of an educational organization which generates, transmits, and disseminates knowledge adopt a scientific approach toward human resource management, considering and paying great attention to their employees as the main assets of the organization. In this regard, this study can clarify the prospect and impacts of managers' self-knowledge and explain the role of creating organizational health and quality of work life. Without doubt, creating a healthy organizational climate in a learning environment can play a significant role in facilitating and accelerating the achievement of educational goals. Since performances of schools and managers have great impacts on the future of our country, having a suitable level of mental health is essential for the people who educate our next generations. Therefore, to select managers who have self-knowledge, this question arises: does self-knowledge have any significant relationship with quality of work life and mental health of managers?

According to what was mentioned earlier, the main objective of the current study was to examine the relationship of self-knowledge with quality of work life and mental health of managers in Nimrouz.

\section{Methods}

The current study followed a descriptive-correlational research design. The statistical population of this study consisted of all high school managers in Nimrouz in the 2014-15 academic year. In this study, due to the small size of the population, census sampling method was applied. Hence, all those 90 individuals were selected as the sample. After collecting data, data analysis was performed on 90 questionnaires filled by 70 male and 20 female managers. Data collection was conducted using questionnaires. To investigate subjects' self-knowledge, Rastogi's Self-Concept Scale (1979) which includes 51 items followed by a 5-point rating scale (totally agree, agree, no idea, disagree, and totally disagree) was used. This scale has 10 subscales (Health and sex appropriateness, abilities, self-confidence, self-acceptance, worthiness, present, past and future, beliefs and convictions, feeling of shame and guilt, sociability). This scale entails 27 negative and 24 positive items. To assess subjects' quality of life, Quality of Work Life Survey developed by Sina Research Institute was used. This survey includes 24 items. Moreover, to examine subjects' mental health, Mental Health Questionnaire (Goldberg General Health Questionnaire) containing 28 items was applied. To determine these questionnaires' validity, content validity was applied. Moreover, using Cronbach's alpha coefficient, their reliability was examined. Table 1 indicates Cronbach's alpha coefficients related to these three questionnaires.

In the current study, to analyze research questions attempted to examine the relationship of self-knowledge with quality of work life and mental health of managers in Nimrouz, the Pearson correlation coefficient, regression analysis, independent t-test, and one-way analysis of variance were applied. It should be noted that all statistical calculations were conducted using SPSS v.18.

General Health Questionnaire (GHQ-28): Goldberg and Hiller's 28-item general health questionnaire is the most known screening tool to evaluate non-psychotic mental disorders. The 28-item questionnaire was developed by Goldberg and Hiller (24) to screen mental disorders in general population. The form used in the present study includes four scales each having seven items measuring four categories of non-psychiatric disorders, including 1-somatic symptoms; 2-anxiety and sleep disorders; 3-social dysfunctioning; and 4-depression and suicidal tendencies. The reliability of the questionnaire was estimated by the Palahang, Nasr and Baraheni (24) as 0.91. In Yaghubi et al.'s (24) study, the test-retest reliability coefficient and Cronbach alpha value were estimated 0.81. Shokri et al. (25) reported the correlation between data from two questionnaires of GHQ and 90SCL as 0.87 . In Taghavi's (26) study, the reliability coefficients were estimated as follows: total questionnaire: 0.72 , somatic symptoms: 0.60 , anxiety and sleep disorders: 0.68 , social dysfunctioning: 0.57 and depression: 0.58 .

\section{Results}

\subsection{Descriptive Data Analysis}

In this section, subjects' demographic information, including their gender, level of education, and years of experience, is presented. 
Table 1. Alpha coefficients indicating these questionnaires' reliability.

\begin{tabular}{cccc}
\hline & Variables & Number of questions & Alpha \\
\hline 1 & Self-knowledge & 51 & 0.89 \\
2 & Mental health & 28 & 0.81 \\
3 & Quality of work life & 24 & 0.80 \\
\hline
\end{tabular}

According to Table 2, 70 respondents (78\%) were male and 20 respondents (22\%) were female.

Considering Table 3, respectively 23 (25.6\%), 63 (70\%), and 4 individuals (4.4\%) had an associate degree, a B.A. degree, and a M.A degree.

Based on Table 4, 8 individuals (8.9\%) had 6 - 10 years of experience, 17 individuals (18.9\%) had 11 - 15 years of experience, and 65 individuals (72.2\%) had more than 16 years of experience.

Mean and standard deviation of quality of work life, self-knowledge, and organizational health are indicated in Table 5 which are $53.79 \pm 9.98,129.72 \pm 18.84$, and $59.34 \pm 11.22$, respectively.

Table 6 demonstrates mean and standard deviation of dimensions of self-knowledge. Among the dimensions of self-knowledge, abilities (17.2), worthiness (16.55), health and sex appropriateness (15.02), presents, past, and future (14.55), feeling of shame and guilt (13.83), self-confidence (12.33), emotionality (12.22), self-acceptance (10.3), sociability (8.81) and beliefs and convictions (7.02) respectively have the highest mean.

Table 7 represents mean and standard deviation of general health dimensions. Among these dimensions, depression symptoms (15.27), anxiety and insomnia (15.22), somatic symptoms (15.11), and social dysfunction (13.74) respectively have the highest mean.

\subsection{Inferential Data Analysis}

Given the results demonstrated in Table 8, the obtained data related to quality of work life, self-knowledge, and general health is normal ( $p$-value $>0.05$ ). Therefore, parametric tests (independent t-test, one-way analysis of variance, the Pearson correlation coefficient, and multiple regression analysis) can be used to test the hypotheses.

First Objective: Determining the relationship between quality of work life and self-knowledge of managers.

Results of the Pearson correlation coefficient with error less than 5\% indicate that there is a direct and positive statistically significant relationship between quality of work life and self-knowledge $(r=0.287, p$-value $<$ 0.05 ) in a way that with an increase in self-knowledge, quality of work life also increases (Table 9).

Second Objective: Determining the relationship between quality of work life and general health of managers.

Results of the Pearson correlation coefficient with error less than $5 \%$ indicate that there is a statistically significant relationship between quality of work life and general health $(r=0.406, p$-value $<0.05)$ and this relationship is significant and positive in a way that with an increase in general health, quality of work life also increases (Table 10).

Third Objective: Determining the relationship between self-knowledge and general health of managers.

Results of the Pearson correlation coefficient with error less than $5 \%$ indicate that there is a statistically significant relationship between self-knowledge and general health $(r=0.585, p$-value $<0.05)$ and this relationship is significant and positive in a way that with an increase in self-knowledge, quality of work life also increases (Table 11).

Fourth Objective: Determining the relationship between self-knowledge and quality of work life of managers.

Results of the Pearson correlation coefficient with error less than $5 \%$ indicate that quality of work life is significantly related to health and sex appropriateness $(r=0.405)$, abilities $(r=0.225)$, self-confidence $(r=0.534)$, worthiness $(r=0.448)$, present, past and future $(r=0.224)$, beliefs and convictions $(r=0.224)$. These correlations are positive and direct ( $p$-value $<0.05)$. Moreover, feeling of shame and guilt $(r=0.273)$ has a diverse significant relationship with quality of work life $(p$-value $<0.05)$. However, self-acceptance, sociability, and emotionality have no significant relationship with quality of work life ( $p$-value $>0.05$ ) (Table 12).

Fifth Objective: Determining the relationship between general health and quality of work life of managers.

Results of the Pearson correlation coefficient with error less than $5 \%$ indicate that quality of work life is significantly correlated with somatic symptoms $(r=0.313)$, anxiety and insomnia $(r=0.509)$, and social dysfunc- 
Table 2. Frequency distribution of subjects’ based on gender.

\begin{tabular}{cccc}
\hline Gender & N & Percentage \\
\hline Female & 20 & 22.0 \\
Male & 70 & 78.0 \\
Total & 90 & 100.0 \\
\hline
\end{tabular}

Table 3. Frequency distribution of subjects based on level of education.

\begin{tabular}{cccc}
\hline Level of education & N & Percentage \\
\hline Associate degree & 23 & 25.6 \\
B.A. & 63 & 70.0 \\
M.A. & 4 & 4.4 \\
Total & 90 & 100.0 \\
\hline
\end{tabular}

Table 4. Frequency distribution of subjects based on years of experience.

\begin{tabular}{cccc}
\hline Years of experience & N & Percentage \\
\hline $6-10$ years & 8 & 8.9 \\
$11-15$ years & 17 & 18.9 \\
More than 16 years & 65 & 72.2 \\
Total & 90 & 100.0 \\
\hline
\end{tabular}

Table 5. Mean and standard deviation of quality of work life, self-knowledge, and general health.

\begin{tabular}{cccccc}
\hline Variable & N & Mean & SD & Min & Max \\
\hline Quality of work life & & 53.79 & 9.98 & 38 & 83 \\
Self-knowledge & 90 & 129.72 & 18.84 & 93 & 160 \\
General health & & 59.34 & 11.22 & 25 & 80 \\
\hline
\end{tabular}

Table 6. Mean and standard deviation of dimensions of self-knowledge.

\begin{tabular}{|c|c|c|c|c|c|}
\hline Dimensions of self-knowledge & $\mathrm{N}$ & Mean & SD & Min & Max \\
\hline Health and sex appropriateness & \multirow{10}{*}{90} & 15.02 & 3.42 & 9 & 24 \\
\hline Abilities & & 17.2 & 3.91 & 10 & 26 \\
\hline Self-confidence & & 12.33 & 1.85 & 9 & 17 \\
\hline Self-acceptance & & 10.3 & 2.55 & 5 & 16 \\
\hline Worthiness & & 16.5 & 3.55 & 10 & 22 \\
\hline Present, past and future & & 14.55 & 3.06 & 9 & 23 \\
\hline Beliefs and convictions & & 7.02 & 2.45 & 3 & 14 \\
\hline Feeling of shame and guilt & & 13.83 & 3.44 & 6 & 24 \\
\hline Sociability & & 8.81 & 2.75 & 5 & 14 \\
\hline Emotionality & & 12.22 & 3.54 & 5 & 19 \\
\hline
\end{tabular}


Table 7. Mean and standard deviation of general health dimensions.

\begin{tabular}{ccccccc}
\hline Dimensions of general health & N & Mean & SD & Min & Max \\
\hline Somatic symptoms & & 15.11 & 4.17 & 4 & 21 \\
Anxiety and insomnia & & 15.22 & 3.48 & 7 & 21 \\
Social dysfunction & 90 & 13.74 & 2.35 & 7 & 19 \\
Depression symptoms & & 15.27 & 4.19 & 6 & 21 \\
\hline
\end{tabular}

Table 8. Kolmogorov-Smirnov test conducted to evaluate the normality of data distribution.

\begin{tabular}{cc}
\hline Variable & $p$-value \\
\hline Quality of work life & 0.086 \\
Self-knowledge & 0.279 \\
Organizational health & 0.167 \\
\hline
\end{tabular}

Table 9. The relationship between quality of life and self-knowledge.

\begin{tabular}{cccc}
\hline \multirow{2}{*}{ Variables } & \multicolumn{2}{c}{ Self-knowledge } \\
\cline { 2 - 4 } & $\mathrm{N}$ & Pearson correlation coefficient & $p$-value \\
\hline Quality of work life & 90 & 0.287 & 0.006 \\
\hline
\end{tabular}

Table 10. The relationship between quality of life and general health.

\begin{tabular}{cccc}
\hline \multirow{2}{*}{ Variables } & \multicolumn{2}{c}{ General health } \\
\cline { 2 - 4 } & $\mathrm{N}$ & Pearson correlation coefficient & $p$-value \\
\hline Quality of work life & 90 & 0.406 & 0.000 \\
\hline
\end{tabular}

Table 11. The relationship between self-knowledge and general health.

\begin{tabular}{cccc}
\hline \multirow{2}{*}{ Variables } & \multicolumn{2}{c}{ General health } \\
\cline { 2 - 4 } & $\mathrm{N}$ & Pearson correlation coefficient & $p$-value \\
\hline Self-knowledge & 90 & 0.585 & 0.000 \\
\hline
\end{tabular}

Table 12. The relationship between self-knowledge and quality of work life.

\begin{tabular}{|cccc}
\hline & Self-knowledge & & \\
\hline Dimensions of self-knowledge & $\mathrm{N}$ & Pearson correlation coefficient & $p$-value \\
\hline Health and sex appropriateness & & 0.405 & 0.000 \\
Abilities & 0.225 & 0.033 \\
Self-confidence & & 0.000 \\
Self-acceptance & 90 & -0.114 & 0.283 \\
Worthiness & & 0.448 & 0.000 \\
Present, past and future & & 0.224 & 0.034 \\
Beliefs and convictions & & 0.224 & 0.034 \\
Feeling of shame and guilt & -0.273 & 0.009 \\
Sociability & 0.143 & 0.18 \\
Emotionality & & 0.077 & 0.471 \\
\hline
\end{tabular}


tion $(r=0.405)$. These correlations are positive and direct $(p$-value $<0.05)$. However, depression symptoms have no significant relationship with quality of work life ( $p$-value $>0.05$ ) (Table 13).

Sixth Objective: Determining the relationship of quality of work life, self-knowledge, and general health considering demographic information.

\section{3. *Independent t-Test 1}

Considering Table 14, given the Leuven's test, the assumption of equal variances is confirmed ( $p$-value $>0.05$ ). Moreover, considering the results of independent t-test, there is a statistically significant relationship between quality of work life and gender ( $p$-value $<0.05)$ such that females' mean score on quality of work life is higher than that of males'.

\section{4. *Independent t-Test 2}

Considering Table 15, given the Leuven's test, the assumption of equal variances is not confirmed ( $p$-value < 0.05). Moreover, considering the results of independent t-test, there is no statistically significant relationship between and gender ( $p$-value $<0.05$ ) such that females' mean score on self-knowledge is equal to that of males'.

\section{5. *Independent t-Test 3}

Considering Table 16, given the Leuven's test, the assumption of equal variances is confirmed ( $p$-value $<0.05$ ). Moreover, considering the results of independent t-test, there is a statistically significant relationship between general health and gender ( $p$-value $>0.05$ ) such that females' mean score on mental health is higher than that of males'.

Table 13. The relationship between general health and quality of work life.

\begin{tabular}{cccc}
\hline \multicolumn{3}{c}{ Quality of work life } & \\
\hline Dimensions of general health & $\mathrm{N}$ & Pearson correlation coefficient & $p$-value \\
\hline Somatic symptoms & & 0.313 & 0.003 \\
Anxiety and insomnia & \multirow{2}{*}{90} & 0.509 & 0.000 \\
Social dysfunction & & 0.405 & 0.000 \\
Depression symptoms & & 0.127 & 0.234 \\
\hline
\end{tabular}

Table 14. Comparing mean of quality of work life based on gender.

\begin{tabular}{cccc}
\hline Quality of work life & \multicolumn{2}{c}{ Gender } & Female \\
\cline { 2 - 3 } N & Male & 20 \\
Mean & 70 & 57.15 \\
Standard deviation \\
$p$-value
\end{tabular}

Table 15. Comparing mean of self-knowledge based on gender.

\begin{tabular}{|c|c|c|}
\hline \multirow{2}{*}{ Self-knowledge } & \multicolumn{2}{|c|}{ Gender } \\
\hline & Male & Female \\
\hline $\mathrm{N}$ & 70 & 20 \\
\hline Mean & 125.05 & 126.20 \\
\hline Standard deviation & 17.52 & 20.72 \\
\hline$p$-value & \multicolumn{2}{|c|}{0.000} \\
\hline
\end{tabular}




\section{6. * One-Way Analysis of Variance 1}

Considering Table 17, the results of one-way analysis of variance indicate that there is a statistically significant relationship between quality of work life and level of education ( $p$-value $<0.05)$. With regard to Turkey's HSD test, mean of quality of work life of managers who have a B.A. degree is higher than that of managers with other degrees.

\section{7. *One-Way Analysis of Variance 2}

Considering Table 18, the results of one-way analysis of variance indicate that there is no statistically significant relationship between self-knowledge and level of education ( $p$-value $>0.05$ ).

\section{8. * One-Way Analysis of Variance 3}

Considering Table 19, the results of one-way analysis of variance indicate that there is a statistically significant difference between the mean score on general health and level of education ( $p$-value $<0.05$ ). With regard to Turkey's HSD test, mean of general health of managers who have a M.A. degree is higher than that of managers with other degrees.

\section{9. *One-Way Analysis of Variance 4}

Considering Table 20, the results of one-way analysis of variance indicate that there is a statistically significant relationship between quality of work life and years of experience ( $p$-value $<0.05$ ). With regard to Turkey's HSD test, mean of quality of work life of managers who have 11 - 15 years of experience is higher than that of other managers.

\subsection{0. *0ne-Way Analysis of Variance 5}

Considering Table 21, the results of one-way analysis of variance indicate that there is no statistically sig nificant relationship between self-knowledge and years of experience ( $p$-value $>0.05$ ).

Table 16. Comparing mean of general health based on gender.

\begin{tabular}{cccc}
\hline General health & \multicolumn{2}{c}{ Gender } & Female \\
\cline { 2 - 3 } $\mathrm{N}$ & Male & 20 \\
Mean & 70 & 61.34 \\
Standard deviation & 52.35 & 10.73 \\
$p$-value & & 0.079 \\
\hline
\end{tabular}

Table 17. Comparing mean of quality of work life based on level of education.

\begin{tabular}{cccccc}
\hline Level of education & N & Mean & SD & $p$-value \\
\hline Associate degree & 23 & 49.26 & 7.67 & 0.038 \\
B.A. & 63 & 55.43 & 10.14 & 15.16 \\
M.A. & 4 & 54.0 & \\
\hline
\end{tabular}

Table 18. Comparing mean of self-knowledge based on level of education.

\begin{tabular}{ccccc}
\hline Level of education & $\mathrm{N}$ & Mean & SD & 16.6 \\
Associate degree & 23 & 129.73 & 19.29 & 0.384 \\
B.A. & 63 & 130.52 & 117.0 & 24.25 \\
M.A. & 4 & 140 \\
\hline
\end{tabular}




\subsection{1. * One-Way Analysis of Variance 6}

Considering Table 22, the results of one-way analysis of variance indicate that there is no statistically significant relationship between general health and field of study ( $p$-value $>0.05$ ).

Seventh Objective: Determining the predictive model of dimensions of self-knowledge based on quality of work life.

According to Table 23, the amount of F-statistic, with the degree of freedom of 10 and 79, is greater than the critical value, at the $95 \%$ confidence level. In this regard, there is a significant correlation between dimensions of self-knowledge and quality of work life ( $p$-value $<0.05$ ). Multiple correlation coefficient is equal to 0.834 and modified coefficient of determination is equal to 0.696 . Therefore, $69.6 \%$ of the variance of quality of work life can be explained by various dimensions of self-knowledge altogether. Other variances relate to other unknown factors that are not included in the current study.

Given these results (Table 24), among dimensions of self-knowledge, beta coefficients of abilities (0.586),

Table 19. Comparing mean of general health based on level of education.

\begin{tabular}{ccccc}
\hline Level of education & $\mathrm{N}$ & Mean & SD & $p$-value \\
\hline Associate degree & 23 & 63.69 & 7.33 & 12.16 \\
B.A. & 63 & 57.38 & 9.77 & 0.037 \\
M.A. & 4 & 65.25 & \\
\hline
\end{tabular}

Table 20. Comparing mean of quality of work life based on years of experience.

\begin{tabular}{ccccc}
\hline Years of experience & N & Mean & SD & $p$-value \\
\hline 6 - 10 years & 8 & 60.25 & 5.36 & 0.000 \\
$11-15$ years & 17 & 60.88 & 7.48 & 9.78 \\
More than 16 years & 65 & 51.14 & \\
\hline
\end{tabular}

Table 21. Comparing mean of self-knowledge based on years of experience.

\begin{tabular}{ccccc}
\hline Years of experience & $\mathrm{N}$ & Mean & SD & $p$-value \\
\hline 6 - 10 years & 8 & 63.69 & 7.33 & 0.073 \\
11 - 15 years & 17 & 57.38 & 12.16 & 9.77 \\
More than 16 years & 65 & 65.25 & \\
\hline
\end{tabular}

Table 22. Comparing mean of general health based on years of experience.

\begin{tabular}{ccccc}
\hline Years of experience & N & Mean & SD & p-value \\
\hline 6 - 10 years & 8 & 65.5 & 6.89 & 0.158 \\
11 - 15 years & 17 & 61.23 & 7.73 & 12.15 \\
More than 16 years & 65 & 58.09 & \\
\hline
\end{tabular}

Table 23. Multiple regression analysis (dependent on quality of work life).

\begin{tabular}{ccccccc}
\hline Source & Sum of squares & DF & Mean square & $\mathrm{R}^{2}$ & $\mathrm{R}$ & F-statistic \\
\hline Regression & 6169.872 & 10 & 616.987 & & & \\
Residual & 2699.117 & 79 & 34.166 & 0.696 & 0.834 & 18.058 \\
Total & 8868.989 & 89 & - & & \\
\hline
\end{tabular}


self-confidence (0.55), present, past, and future $(-0.401)$, beliefs and convictions $(0.33)$, and feeling of shame and guilt $(-0.482)$ are statistically significant $(p$-value $<0.05)$. However, beta coefficients of health and sex appropriateness $(0.181)$, self-acceptance $(-0.308)$, worthiness $(0.146)$, sociability $(-0.051)$, and emotionality $(-0.157)$ are not statistically significant ( $p$-value $>0.05$ ). Hence, the predictive model can be presented as follows:

$$
\begin{aligned}
Y= & 25.122+0.529 X_{1}+1.495 X_{2}+2.962 X_{3}-1.205 X_{4}+0.412 X_{5} \\
& -1.305 X_{6}+1.344 X_{7}-1.397 X_{8}-0.186 X_{9}-0.443 X_{10}
\end{aligned}
$$

$Y$ : Quality of work life; $X_{1}$ : Health and sex appropriateness; $X_{2}$ : Abilities; $X_{3}$ : Self-confidence; $X_{4}$ : Self-acceptance; $X_{5}$ : Worthiness; $X_{6}$ : Present, past, and future; $X_{7}$ : Beliefs and convictions; $X_{8}$ : Feeling of shame and guilt; $X_{9}$ : Sociability; $X_{10}$ : Emotionality. Among significant variables, self-confidence is the most effective variable.

Eighth Objective: Determining the predictive model of dimensions of general health based on quality of work life.

According to Table 25, the amount of F-statistic, with the degree of freedom of 85 and 4, is greater than the critical value, at the $95 \%$ confidence level. In this regard, there is a significant correlation between dimensions of general health and quality of work life ( $p$-value $<0.05$ ). Multiple correlation coefficient is equal to 0.58 and modified coefficient of determination is equal to 0.337 . Therefore, $33.7 \%$ of the variance of quality of work life can be explained by various dimensions of general health altogether. Other variances relate to other unknown factors that are not included in the current study.

Given these results (Table 26), among dimensions of general health, beta coefficients of anxiety and insomnia $(-0.631)$ and social dysfunction $(-0.313)$ are statistically significant $(p$-value $<0.05)$. However, beta coefficients of somatic symptoms ( 0.297$)$ and depression symptoms $(0.145)$ are not statistically significant $(p$-value $>0.05)$. Hence, the predictive model can be presented as follows:

$$
Y=83.56+0.711 X_{1}-1.808 X_{2}-1.329 X_{3}+0.345 X_{4}
$$

$Y$ : Quality of work life; $X_{1}$ : Somatic symptoms; $X_{2}$ : Anxiety and insomnia; $X_{3}$ : Social dysfunction; $X_{4}$ : De pression symptoms. Among significant variables, anxiety and insomnia is the most effective variable.

Table 24. Relationship between each dimension of self-knowledge based on quality of work life.

\begin{tabular}{ccccc}
\hline Functions & B & Beta & t-statistic & $p$-value \\
\hline Constant value & 25.122 & - & 4.586 & 0.000 \\
Health and sex appropriateness & 0.529 & 0.181 & 1.717 & 0.09 \\
Abilities & 1.495 & 0.586 & 4.171 & 0.000 \\
Self-confidence & 2.962 & 0.55 & 5.516 & 0.000 \\
Self-acceptance & -1.205 & -0.308 & -1.929 & 0.057 \\
Worthiness & 0.412 & 0.146 & 1.243 & 0.218 \\
Present, past and future & -1.305 & -0.401 & 2.894 & 0.005 \\
Beliefs and convictions & 1.344 & 0.33 & 2.569 & 0.012 \\
Feeling of shame and guilt & -1.397 & -0.482 & -4.524 & 0.000 \\
Sociability & -0.186 & -0.051 & -0.437 & 0.663 \\
Emotionality & -0.443 & -0.157 & -1.206 & 0.231 \\
\hline
\end{tabular}

Table 25. Multiple regression analysis (dependent on quality of work life).

\begin{tabular}{ccccccc}
\hline Source & Sum of squares & DF & Mean square & $\mathrm{R}^{2}$ & R & F-statistic \\
\hline Regression & 2985.317 & 4 & 746.329 & & & \\
Residual & 5883.672 & 85 & 69.22 & 0.337 & 0.58 & 10.782 \\
Total & 8868.989 & 89 & - & & \\
\hline
\end{tabular}


Ninth Objective: Determining the predictive model of dimensions of self-knowledge based on general health

According to Table 27, the amount of F-statistic, with the degree of freedom of 10 and 79, is greater than the critical value, at the $95 \%$ confidence level. In this regard, there is a significant correlation between dimensions of self-knowledge and general health ( $p$-value $<0.05$ ). Multiple correlation coefficient is equal to 0.774 and modified coefficient of determination is equal to 0.6 . Therefore, $60 \%$ of the variance of general health can be explained by various dimensions of self-knowledge altogether. Other variances relate to other unknown factors that are not included in the current study.

Given these results (Table 28), among dimensions of self-knowledge, beliefs and convictions (0.216), is statistically significant ( $p$-value $<0.05$ ). However, beta coefficients of beta coefficients of health and sex appropriateness $(-0.167)$, abilities $(-0.24)$, self-confidence $(-0.202)$, self-acceptance $(-0.138)$, present, past, and future (0.289), worthiness $(-0.12)$, feeling of shame and guilt $(0.216)$ sociability $(-0.203)$, and emotionality $(-0.238)$ are not statistically significant $(p$-value $>0.05)$. Hence, the predictive model can be presented as follows:

$$
\begin{aligned}
Y= & 96.543-0.548 X_{1}-0.688 X_{2}-1.222 X_{3}-0.608 X_{4}-0.38 X_{5} \\
& +1.058 X_{6}-2.362 X_{7}+0.705 X_{8}-0.827 X_{9}+0.755 X_{10}
\end{aligned}
$$

Table 26. Relationship between each dimension of general health based on quality of work life.

\begin{tabular}{ccccc}
\hline Functions & B & Beta & t-statistic & $p$-value \\
\hline Constant value & 83.56 & - & 15.323 & 0.000 \\
Somatic symptoms & 0.711 & 0.297 & 1.987 & 0.051 \\
Anxiety and insomnia & 1.808 & -0.631 & -4.202 & 0.000 \\
Social dysfunction & 1.329 & -0.313 & -2.625 & 0.01 \\
Depression symptoms & 0.345 & 0.145 & 1.347 & 0.182
\end{tabular}

Table 27. Multiple regression analysis (dependent on general health).

\begin{tabular}{ccccccc}
\hline Source & Sum of squares & DF & Mean square & $\mathrm{R}^{2}$ & $\mathrm{R}$ & F-statistic \\
\hline Regression & 6725.105 & 10 & 672.51 & & & \\
Residual & 4479.218 & 79 & 56.699 & 0.6 & 0.775 & 11.861 \\
Total & 11204.322 & 89 & - & \\
\hline
\end{tabular}

Table 28. Relationship between each dimension of self-knowledge based on general health.

\begin{tabular}{ccccc}
\hline Functions & B & Beta & t-statistic & $p$-value \\
\hline Constant value & 96.543 & - & 13.682 & 0.000 \\
Health and sex appropriateness & -0.548 & -0.167 & -1.381 & 0.171 \\
Abilities & -0.688 & -0.24 & -1.49 & 0.14 \\
Self-confidence & -1.222 & -0.202 & -1.767 & 0.081 \\
Self-acceptance & -0.608 & -0.138 & -0.756 & 0.452 \\
Worthiness & -0.38 & -0.12 & -0.892 & 0.375 \\
Present, past and future & 1.058 & 0.289 & 1.82 & 0.073 \\
Beliefs and convictions & -2.362 & -0.516 & -3.503 & 0.001 \\
Feeling of shame and guilt & 0.705 & 0.216 & 1.773 & 0.08 \\
Sociability & -0.827 & -0.203 & -1.508 & 0.136 \\
Emotionality & 0.755 & 0.238 & 1.595 & 0.115 \\
\hline
\end{tabular}


$Y$ : Quality of work life; $X_{1}$ : Health and sex appropriateness; $X_{2}$ : Abilities; $X_{3}$ : Self-confidence; $X_{4}$ : Self-acceptance; $X_{5}$ : Worthiness; $X_{6}$ : Present, past, and future; $X_{7}$ : Beliefs and convictions; $X_{8}$ : Feeling of shame and guilt; $X_{9}$ : Sociability; $\mathrm{X}_{10}$ : Emotionality.

When scoring the General Health Questionnaire, a score of 0 - 22 indicates no or minimum general health, a score of 22 - 40 indicates low general health, a score of 41 - 60 demonstrates moderate general health, and a score 61 - 84 shows high general health. For each dimension of general health a score of 0 - 6, 7 - 11, 12 - 16, and 17 - 21 is respectively considered for no, low, average, and high general health.

With regard to the results demonstrated in Table 29, 4 managers (4.4\%) have low general health, 48 managers (53.3\%) have moderate general health, and 38 managers (42.2\%) have high general health.

\section{Discussions}

First Research Question: Determining the relationship between quality of work life and self-knowledge of managers.

Results of the Pearson correlation coefficient with error less than 5\% indicated that there was a direct and positive statistically significant relationship between quality of work life and self-knowledge $(\mathrm{r}=0.287, p$-value $<0.05$ ) in a way that with an increase in self-knowledge, quality of work life also increased.

Second Question: Determining the relationship between quality of work life and general health of managers.

Results of the Pearson correlation coefficient with error less than $5 \%$ indicated that there was a statistically significant relationship between quality of work life and general health $(r=0.406$, $p$-value $<0.05)$ and this relationship was significant and positive in a way that with an increase in general health, quality of work life also increased. This finding is in line with the results of Mohammadi (1999) and Saedi et al. (2010) who indicated that there was a direct significant relationship between quality of work life and organizational health.

Third Question: Determining the relationship between self-knowledge and general health of managers.

Results of the Pearson correlation coefficient with error less than 5\% indicated that there was a statistically significant relationship between self-knowledge and general health $(r=0.585$, $\mathrm{p}$-value $<0.05)$ and this relationship was significant and positive in a way that with an increase in self-knowledge, quality of work life also increased.

Fourth Question: Determining the relationship between self-knowledge and quality of work life of managers.

Results of the Pearson correlation coefficient with error less than 5\% indicated that quality of work life was significantly related to health and sex appropriateness $(r=0.405)$, abilities $(r=0.225)$, self-confidence $(r=$ $0.534)$, worthiness $(r=0.448)$, present, past and future $(r=0.224)$, beliefs and convictions $(r=0.224)$. These correlations were positive and direct $(p$-value $<0.05)$. Moreover, feeling of shame and guilt $(r=0.273)$ had a diverse significant relationship with quality of work life ( $p$-value $<0.05)$. However, self-acceptance, sociability, and emotionality had no significant relationship with quality of work life ( $p$-value $>0.05)$.

Fifth Question: Determining the relationship between general health and quality of work life of managers.

Results of the Pearson correlation coefficient with error less than 5\% indicated that quality of work life was significantly correlated with somatic symptoms $(r=0.313)$, anxiety and insomnia $(r=0.509)$, and social dysfunction $(\mathrm{r}=0.405)$. These correlations were positive and direct ( $p$-value $<0.05)$. However, depression symptoms had no significant relationship with quality of work life ( $p$-value $>0.05$ ).

Sixth Question: Determining the relationship of quality of work life, self-knowledge, and general health considering demographic information.

Given the Leuven's test, the assumption of equal variances was confirmed ( $p$-value $>0.05$ ). Moreover, considering the results of independent t-test, there was a statistically significant relationship between quality of

Table 29. Managers' level of general health.

\begin{tabular}{ccc} 
General health & N & Percentage \\
No or minimum & 0 & 0 \\
Low & 4.4 \\
Moderate & 48 & 53.3 \\
High & 38 & 42.2 \\
\hline
\end{tabular}


work life and gender ( $p$-value $<0.05)$ such that females' mean score on quality of work life was higher than that of males'. This result is consistent with the results of Khadivi \& Alei (2007) and Mohammadi (1999) asserting that there was a significant relationship between quality of work life and gender.

Seventh Question: Determining the predictive model of dimensions of self-knowledge based on quality of work life.

There was a significant correlation between dimensions of self-knowledge and quality of work life (p-value < 0.05 ). Multiple correlation coefficient was equal to 0.834 and modified coefficient of determination was equal to 0.696. Therefore, $69.6 \%$ of the variance of quality of work life could be explained by various dimensions of self-knowledge altogether. Other variances related to other unknown factors that were not included in the current study.

Eighth Question: Determining the predictive model of dimensions of general health based on quality of work life.

There was a significant correlation between dimensions of general health and quality of work life ( $p$-value < 0.05). Multiple correlation coefficient was equal to 0.58 and modified coefficient of determination was equal to 0.337. Therefore, $33.7 \%$ of the variance of quality of work life could be explained by various dimensions of general health altogether. Other variances related to other unknown factors that were not included in the current study.

Ninth Question: Determining the predictive model of dimensions of self-knowledge based on general health.

There was a significant correlation between dimensions of self-knowledge and general health ( $p$-value $<0.05$ ). Multiple correlation coefficient was equal to 0.774 and modified coefficient of determination was equal to 0.6. Therefore, $60 \%$ of the variance of general health could be explained by various dimensions of self-knowledge altogether. Other variances related to other unknown factors that were not included in the current study.

\section{Conclusion}

Considering the obtained results, it can be concluded that self-knowledge is directly correlated with quality of work life and mental health. The more the managers' level of self-knowledge is, the higher their quality of work life and mental health will be. Moreover, the results indicated that there was a direct significant relationship between managers' quality of work life and mental health. This finding was not unexpected since quality of work life entailed emotional components including devotion and attachment to work, commitment to the organization, and taking responsibilities which were closely related to mental health. In other words, with an increase in managers' quality of work life, their mental health will also increase. Additionally, findings indicated that among the dimensions of self-knowledge, self-confidence, sociability, and health and sex appropriateness together were able to predict managers' quality of work life. Moreover, feelings of shame and guilt, abilities, and present, past and future were able to predict organizational health variances. Self-knowledge, quality of work life, and organizational health were the variables of the current study which could be affected by various factors. In the present study, it was attempted to examine some of the factors influencing these variables, among which gender, level of education, and years of experience could be mentioned. The findings demonstrated that male and female managers' self-knowledge, quality of work life, and mental health were alike. In relation to managers' level of education, there was a significant difference among managers considering their self-knowledge; however, considering managers' level of education, their quality of work life and mental health were similar. In addition, these results showed that there was a significant difference between managers' self-knowledge and mental health with regard to their years of experience; however, no significant difference was found among managers' quality of work life considering their years of experience.

\section{References}

Gillian, C., \& Callus, R. (2003). The Development of Quality of Work Life Indication; Helping Define Decent Work in Developed Economies, Australia.

Hosseini Frajam, A. S. (2004). Examining and Comparing Quality of Work Life of Teachers in Hamedan. M.A. Thesis, Hamedan: Educational Management.

Keramati, M. R., \& Roshan, M. (2005). The Relationship between Managers' Self-Knowledge and Their Tricks to Manage Conflicts. Novin Insights, 1, 35-48.

Khadivi, A., \& Alei, H. (2007). The Status of Quality of Work Life of Employees Working at Islamic Azad University of 
Tabriz. Journal of Management, 1, 150-172.

Kheirandish, M. (2004). Quality of Work Life and Performance of Staff Working at Iran Khodro Diesel Company. M.A. Thesis, Tehran: Allameh Tabataba'i University.

Krueger, P. et al. (2002). Organization Specific Predictors of Job Satisfaction Findings from a Canadian Multi Sit Quality of Work Life, Health Service Research. http://dx.doi.org/10.1186/1472-6963-2-6

Nazem, F. (2006). Examining the Perception of Quality of Work Life and Its Components in Different Regions of Islamic Azad University. New Thought in Educational Sciences in Islamic Azad University of Roodehen, 1, 12-29.

Neyestani, M., \& Monfarediraz, B. (2009). An Investigation on the Relationship between Managers' Self-Knowledge and Their Tricks to Manage Conflicts in Bojnurd High Schools. Tarbiati Research, 18, 165-184.

Pardakhtchi, M. A., Ahmadi, Gh. A., \& Arezoumand, F. (2009). The Relationship between Quality of Work Life and Job Burnout of Managers and Teachers in Takestan. Journal of Leadership and Educational Administration, Islamic Azad University of Garmsar, 3, 25-50.

Pruijt, H. (2000). Performance and Quality of Working Life. Journal of Organizational Change Management, 13, 389-400. http://dx.doi.org/10.1108/09534810010339077

Riley, A. (2000). The Quality of Work Life, Self-Evaluation and Life Satisfaction among Africans.

Yavari, Y., Amirtash, A. M., \& Tondnevsi, F. (2009). Comparing Quality of Work Life and Its Subscales among Members of Physical Education Faculties and Departments in Public Universities. Sport Science Magazine, 7, 99-109. 